\title{
Numerical study of local scour effects on the lateral pile-soil interaction
}

\author{
Wen-Gang QI \& Fu-Ping GAO \\ Institute of Mechanics, Chinese Academy of Sciences, Beijing, China
}

\begin{abstract}
Local scour usually occurs around offshore pile foundations, which may bring the reduction of both the effective stresses in the surrounding soil and the effective pile embedment. Until now, the effects of local scour on the lateral pile-soil interaction have not been well understood. In this study, a 3-D finite element model for the lateral pile-soil interaction is proposed and verified with experimental results. An improved analysis approach is further presented for evaluating the local scour effects on the lateral pile-soil interaction by extracting $p-y$ curves from the numerical results. The results indicate that scour could induce a significant transition of pile behavior for a monopile typically employed for offshore wind turbines. If the pile exhibits rigid structural behaviors after scour, the pile's tip and shaft resistance may become a significant component of the whole soil resistance, which would render the traditional $p-y$ approach inapplicable. For a given depth below the scour base, the $p-y$ curves get significantly stiffer with increasing scour depth, especially at relatively shallow depths. The scour effects on the variation of $p-y$ curves from the present numerical results are generally consistent with the existing centrifuge results. As the slope angle of scour holes decreases, the effect of the remaining sloping overburden soil above the level of the scour base reduces and the stiffening of the $p-y$ curves at a given depth below the scour base is correspondingly alleviated.
\end{abstract}

\section{INTRODUCTION}

Offshore piles are traditionally applied for supporting offshore platforms in relatively shallow water. Recently the large-diameter monopile is often used as the foundation of offshore wind turbines. Due to a significant wind turbine hub height (approximately 100 meters for a $3 \mathrm{MW}$ turbine), huge lateral force in the order of $5 \mathrm{MN}$ and bending moment in the order of $1 \times 10^{8}$ N.m would be imposed on the foundation. These huge loads pose significant challenge in the design and construction of the foundation.

The lateral pile response is commonly estimated by a load transfer approach, with ' $p-y$ ' curves quantifying the nonlinear interaction between the pile and the surrounding soil. The $p-y$ curves idealise the soil as a series of independent springs distributed along the pile length, with each spring describing the nonlinear relationship between the lateral soil resistance $(p)$ and the lateral deflection of the pile $(y)$. Details on the $p-y$ methodology for analysis of laterally loaded piles can be found in Reese et al. (1974) and Reese and Van Impe (2001).

Local scour would occur around the pile foundations due to the action of waves and current, reducing the pile embedment depth and increasing the load eccentricity (vertical distance between the loading position and the mudline), and further inducing much larger deformations of the pile and changing the profiles of the lateral soil resistance. Local scour effects for laterally loaded piles have not been well reflected in existing $p-y$ method (API, 2011). In an analytical study (Lin et al., 2010), general scour effects were incorporated by updating the parameters at a given depth to account for the overconsolidation induced by removal of a scour depth of sand. Lin et al. (2014) further modified the lateral resistance due to changes in the shallow wedge-type failure mechanism to consider the effects of the local scour. Results indicated that the local scour hole would result in much higher lateral soil resistance for a given depth than for the general scour case, i.e. complete removal of the soil surface layer. Recently, a series of centrifuge tests were conducted by Qi et al. (2015) to investigate the scour effects on $p-y$ curves. A practical approach to incorporate effects of scour on the $p-y$ curves was proposed by adopting an effective soil depth in the determination of $p-y$ curves.

In this study, a 3-D finite element model for lateral pile-soil interaction is proposed. Based on the $p$ $y$ curves extracted from the numerical results, the scour effects on the applicability of the $p-y$ approach are discussed. Moreover, the local scour effects on the $p-y$ curves are investigated and compared with the existing centrifuge test results. 


\subsection{Finite element mesh and boundary conditions}

The interaction between a laterally loaded monopile and the surrounding soil can be considered as a plane-symmetric problem. A 3-D plane-symmetric finite element model is proposed for simulating the pile-soil interaction using the finite element code ABAQUS. Fig. 1 illustrates the typical finite element mesh of the model, which is mainly consisting of the foundation and the surrounding soil. Both the foundation and soil are composed with 3-D 8-node reduced-integration solid elements (C3D8R). The computational grids get denser in the closer proximity to the pile for high computation efficiency. The grid size of the present model has been proved fine enough for ensuring the accuracy of the results, by comparing results between models with different grid sizes. The interfacial behavior is a key issue to efficiently simulate the complex pile-soil interaction. A contact-pair algorithm was adopted to characterize the interfacial constitutive relationships between pile exterior surface and surrounding soil, pile interior surface and soil-plug, respectively.

As illustrated in Fig. 1, the top-side of the soil is treated as a free boundary. The front-side of the model is a plane-symmetric boundary, i.e. both the rotational degrees of freedom in $x$ and $z$ directions and translational degree of freedom in $y$ direction are constrained to zero. At the outside of the soil, the translational degree of freedom in $\mathrm{x}$ and $y$ directions are constrained. At the bottom of the model, the translational degrees of freedom in both $x, y$ and $z$ directions are fixed. In order to avoid the outer boundaries from affecting the results, the width and height of the simulated soil mass is adjusted to each pile diameter. It is observed that the zone of failure does not reach the outer boundaries.

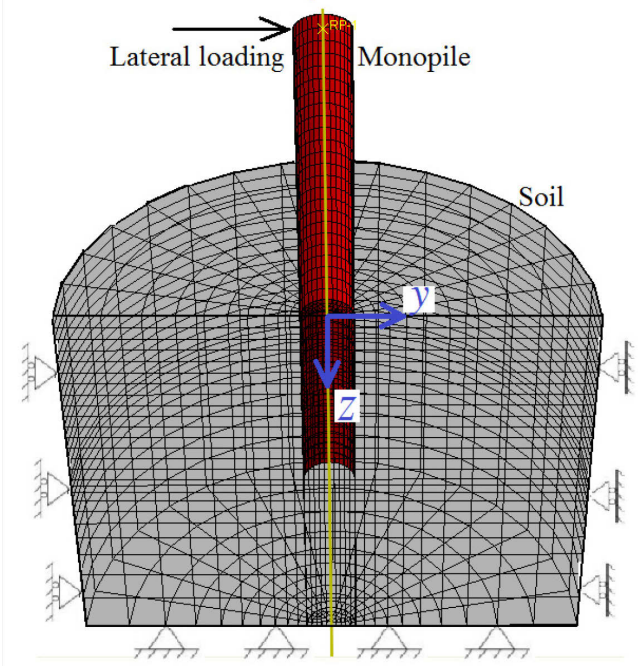

Figure 1. Typical finite element mesh for pile-soil interaction analyses.

\subsection{Constitutive models and properties of materials}

The Mohr-Coulomb plasticity constitutive model (M-C model) is used to simulate the elasto-plastic behavior of the soil for the present drained conditions. The yield function of the $\mathrm{M}-\mathrm{C}$ model is written as (see Knappett \& Craig (2012))

$J-\left(\frac{c}{\tan \phi}+p^{\prime}\right) g(\theta)=0$

in which, $J$ is the deviatoric stress invariant; $c$ is the cohesion strength; $p^{\prime}$ is the mean effective stress;

$g(\theta)=\frac{\sin \phi}{\cos \theta+\sin \theta \sin \phi / \sqrt{3}}$

where $\theta$ is the Lode's angle and $\phi$ is the internal friction angle of the soil.

In the simulations, the parameters of soil are chosen as follows: Poisson's ratio $v=0.3$, the cohesion strength $c=0.5 \mathrm{kPa}$, the buoyant unit weight of the soil $\gamma^{\prime}=10.26 \mathrm{kN} / \mathrm{m}^{3}$. The value of the elastic modulus of the soil $E_{\mathrm{s}}$ varies from $10 \mathrm{MPa}$ to $50 \mathrm{MPa}$ while the angle of internal friction $\phi$ correspondingly changes from $30^{\circ}$ to $40^{\circ}$.

The monopile is made of a steel with Young's modulus of $E_{\mathrm{p}}=210 \mathrm{GPa}$ and Poisson's ratio of $v=0.3$. Various values of pile diameter $D$ (in the range of $2-5 \mathrm{~m}$ ), wall thickness $t_{0}$ (in the range of $0.05-0.15 \mathrm{~m}$ ), embedded pile length $L$ (in the range of 22.5-31.25 m) are adopted in the series of numerical simulations. The pile-soil interface frictional coefficient $(\mu)$ is calculated with the following formula proposed by Randolph \& Wroth (1981)

$\mu=\tan \left[\sin \phi \times \cos \phi /\left(1+\sin ^{2} \phi\right)\right]$

\subsection{Verification with experimental results}

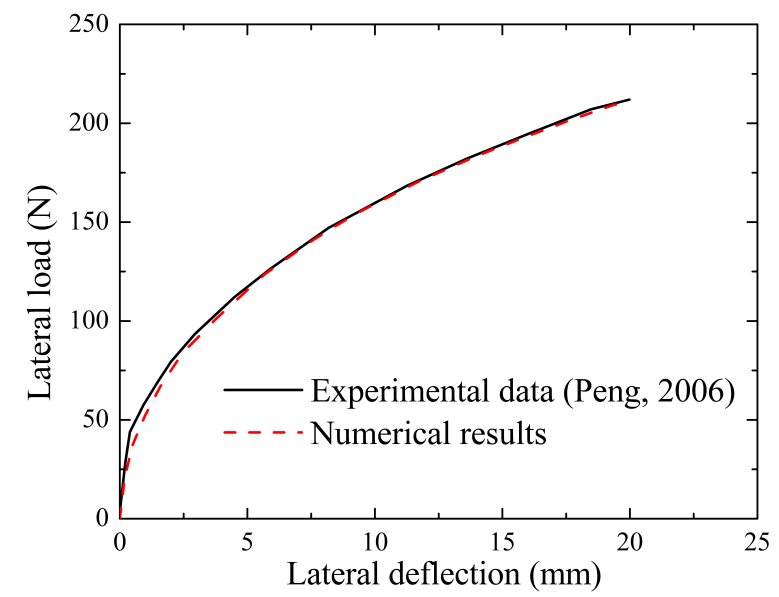

Figure 2. Comparison of horizontal load-displacement curves between FE analyses and experimental tests. $(D=44.5 \mathrm{~mm}$, $L=400 \mathrm{~mm}, \quad \gamma=16.4 \mathrm{kN} / \mathrm{m}^{3}, c=0.5 \mathrm{kPa}, \phi=35.2^{\circ}$ )

To verify the proposed finite element model, comparisons are made between the present numerical result and the experimental result of laterally loaded 
pile tests by Peng (2006), as shown in Fig. 2. The numerical result is in good agreement with the experimental data, which indicates that the present finite element model is capable of simulating the lateral interaction between monopile and surrounding soil.

\section{NUMERICAL RESULTS}

\subsection{Derivation and parameterization of p-y curves}

Numerous 3-D finite element simulations were conducted to provide the data for deriving $p-y$ curves with various pile parameters and soil conditions. Based on the bending moment $(M)$ distribution profiles along the soil depth $(z)$ extracted from the numerical results, the lateral soil resistance $p$ can be obtained by differentiation according to

$$
p=\frac{d^{2} M}{d z^{2}}
$$

To limit the inaccuracy in determining $p$ by differentiating $M$ twice, the piecewise polynomial curve fitting method was adopted (Yang and Liang, 2006). The pile displacement $y$ is directly extracted from the numerical results. Then the $p-y$ curves are obtained by combining the soil resistance and displacement curves at discrete intervals to produce curves for each depth

Fig. 3 shows a typical series of $p-y$ curves derived from the FE results (curves with solid symbols). The stiffness of the $p-y$ curves gradually increases with soil depth. Due to a relatively rigid behavior of the simulated pile, the pile displacement at the middle segment is rather limited and thus the corresponding $p-y$ curves are not presented in Fig. 3 .

The raw $p-y$ data from the numerical results (e.g. data in Fig. 3) could be used to calibrate appropriate mathematical functions to represent the $p-y$ curves. This method is referred to in this paper as the "parameterized approach', after Byrne et al. (2015). An important feature of the parameterized approach is that all 3-D numerical results for a particular case are represented by a single set of parameters (Byrne et al., 2015). Suryasentana \& Lehane (2014) once proposed an exponential relationship to characterize the $p-y$ curves. Following a similar procedure and replacing the CPT end resistance $q_{\mathrm{c}}$ with $E_{\mathrm{s}}$, the lateral resistance is expressed based on a large number of data points for different soil conditions, as

$$
\begin{aligned}
p /\left(\gamma^{\prime} z D\right)= & 0.04\left(E_{s} /\left(\gamma^{\prime} z\right)\right)^{0.86}(z / D)^{0.59} \\
& \times\left[1-\exp \left(-9.3(z / D)^{-0.53}(y / D)^{0.79}\right)\right]
\end{aligned}
$$

The $p-y$ curves predicted using the parameterized approach are compared with the original $p-y$ curves in Fig. 3, generally showing a good consistence in spite of some observable discrepancies (smaller than $20 \%$ ). Fig. 4 compares all the raw $p-y$ data from numerical results and those calculated using the param- eterized approach (Eq. (5)). The comparison shows that the parameterized approach exhibits a good fit to the numerical results.

Note that Eq. (5) is derived for the cases with relatively small pile displacement and careful validation should be conducted while applied to other conditions.

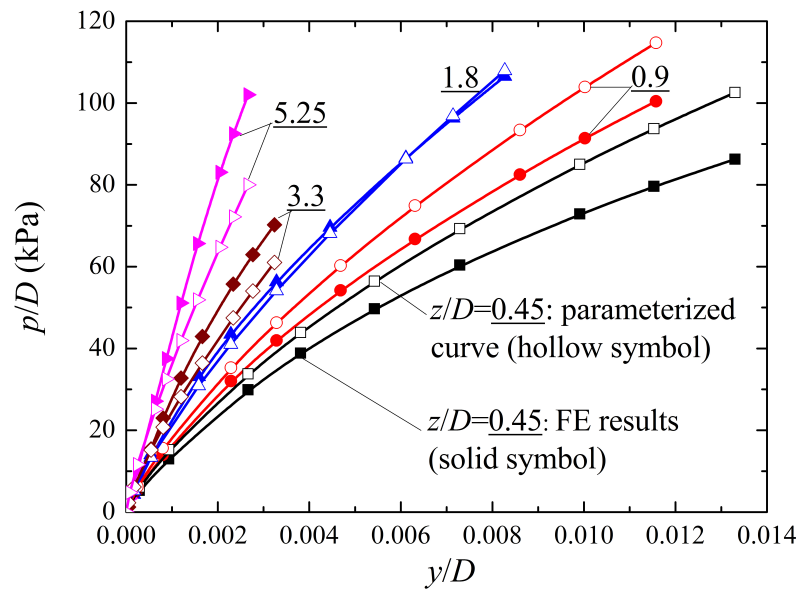

Figure 3. Typical $p-y$ curves derived from FE results $(D=5 \mathrm{~m}$, $L=30 \mathrm{~m}, t_{0}=0.06 \mathrm{~m}, E_{s}=30 \mathrm{MPa}, \phi=35^{\circ}$ )

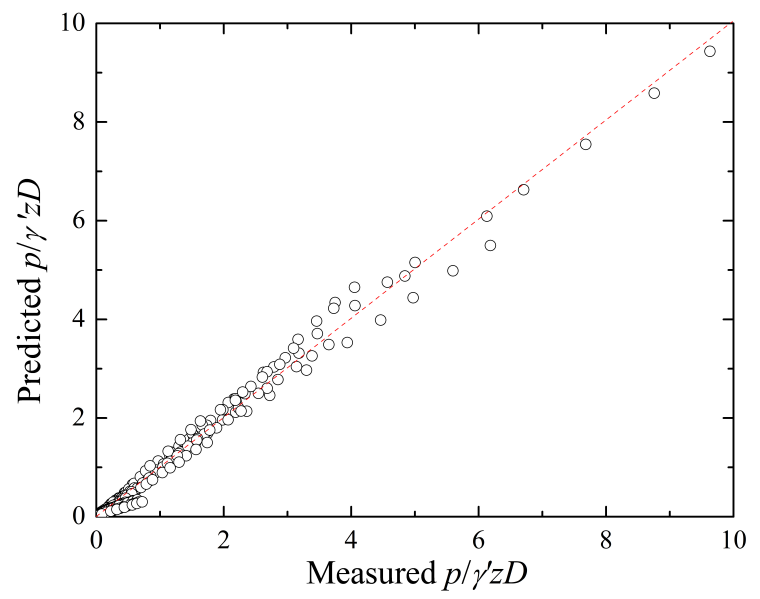

Figure 4. Comparison between FE results and predictions using Eq. (5).

\subsection{Back-analysis using the parameterized p-y curves}

Using the parameterized approach represented by Eq. (5), the lateral response of the monopile can be predicted. The load-displacement curves under a lateral force with a load eccentricity of $e=10 \mathrm{~m}$ is calculated by implementing Eq. (5) in the program Oasys ALP (2013). The comparisons of the results between the 3-D numerical simulation and the $p-y$ approach (parameterized approach) are displayed in Fig. 5. The predictions of the parameterized approach provide a good match to the 3 -D numerical results. 


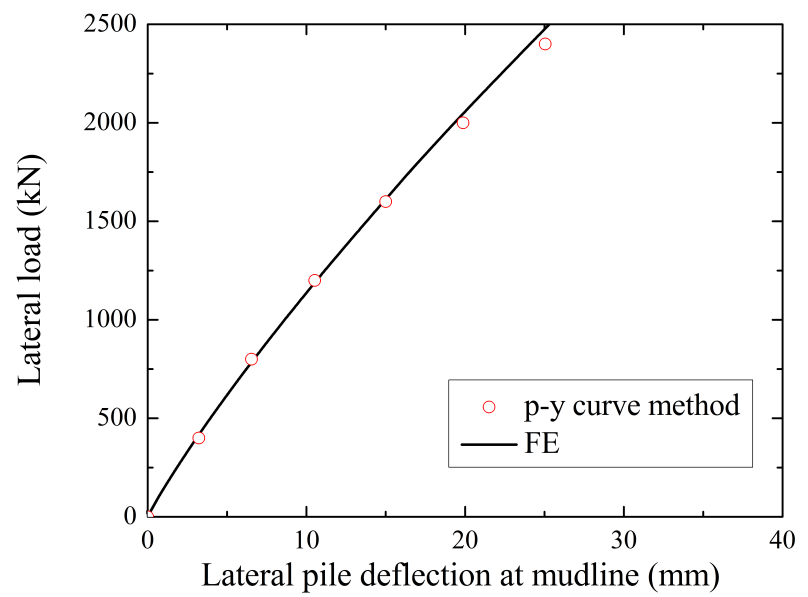

(a)

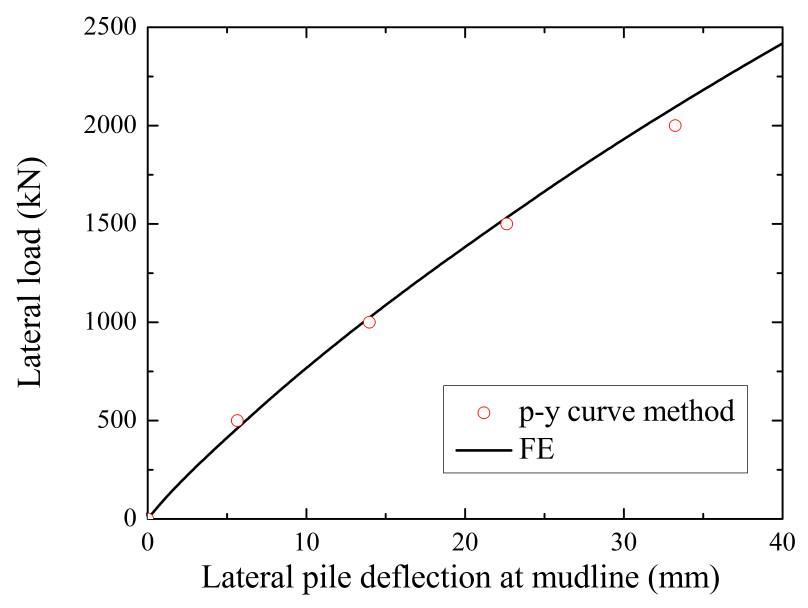

(b)

Figure 5. Comparison of load-displacement curves between 3$\mathrm{D}$ numerical simulation and parameterized $p-y$ approach: (a) $E_{s}=50 \mathrm{MPa}, \phi=40^{\circ}$; (b) $E_{s}=30 \mathrm{MPa}, \phi=35^{\circ} .(D=5 \mathrm{~m}, L=30$ $\left.\mathrm{m}, t_{0}=0.06 \mathrm{~m}\right)$.

\section{DISCUSSIONS}

\subsection{Lateral failure mechanism of monopile}

While evaluating the response of a laterally loaded pile, piles are usually categorized into long/flexible piles and short/rigid piles depending on the failure mechanisms. According to Poulos \& Hull (1989), piles having a length of $L_{\mathrm{c}} / 3<L<L_{\mathrm{c}}$ are proposed as the transition range from flexible to rigid pile, in which $L_{\mathrm{c}}$ represents the critical pile length beyond which any further increase in length doesn't affect the pile head response. For uniform soil, the value of $L_{\mathrm{c}}$ can be calculated by

$L_{c}=4.44 \sqrt[4]{E_{p} I_{p} / E_{s}}$

Thus the range of transition from flexible to rigid pile behavior may be evaluated by

$$
4.8<E_{s} L^{4} / E_{p} I_{p}<388.6
$$

in which $I_{\mathrm{p}}$ denotes the second moment of area of a pile and $E_{\mathrm{p}} I_{\mathrm{p}}$ represents the bending stiffness of the pile. In this paper, we use $\kappa$ to denote the nondimensional parameter $E_{\mathrm{s}} L^{4} / E_{\mathrm{p}} I_{\mathrm{p}}$ for simplicity, i.e.

$$
\kappa=E_{s} L^{4} / E_{p} I_{p}
$$

Fig. 6 illustrates the lateral failure mechanisms for flexible piles and rigid piles, respectively (see Gao et al., 2015). For flexible piles, pile deflections and bending moments induced by the lateral loading are confined to the upper part of the pile and the pile embedment depth has insignificant effect on the pile response, while short piles rotate as a whole and develop a 'toe-kick' phenomenon under the lateral and moment loading. The displacement contour of monopile and soil under lateral loads from the numerical simulations are compared for two typical values of $\kappa=324.7$ and $\kappa=8.3$ in Fig. 7. Two different lateral failure mechanism (i.e. rigid and flexible) are clearly identified.

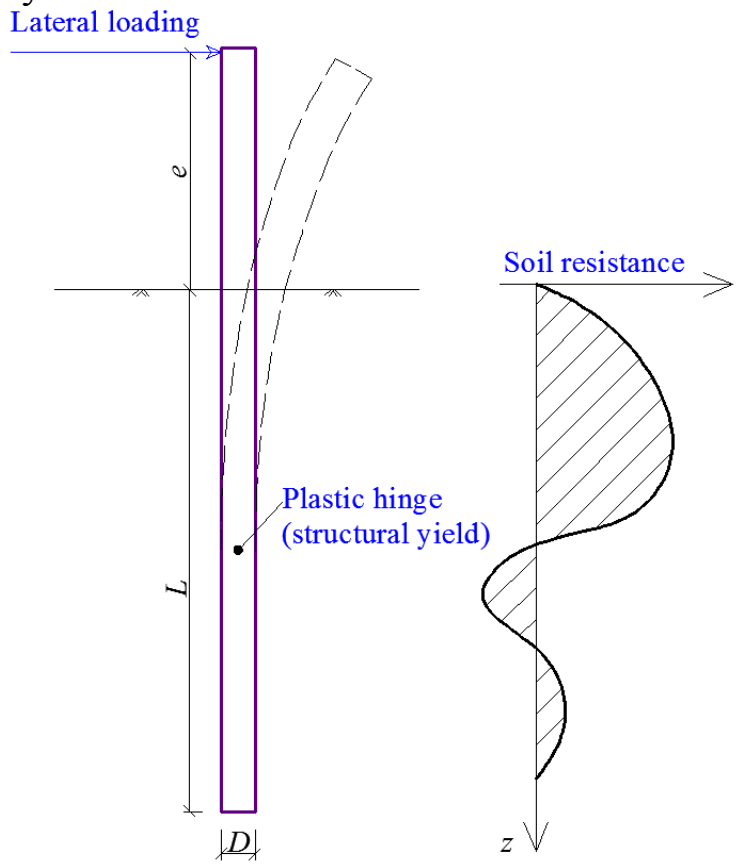

(a)

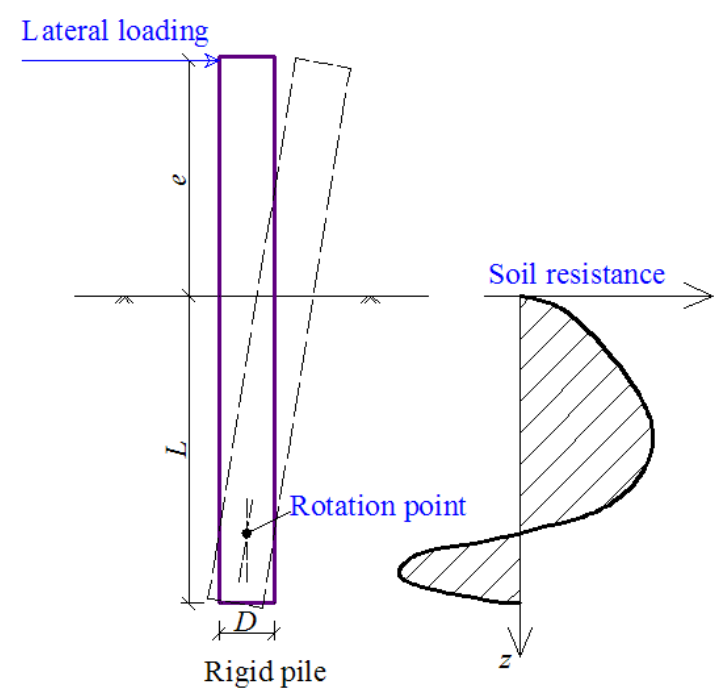

(b)

Figure 6. Lateral failure mechanism for (a) long/flexible piles; and (b) short/rigid piles. 


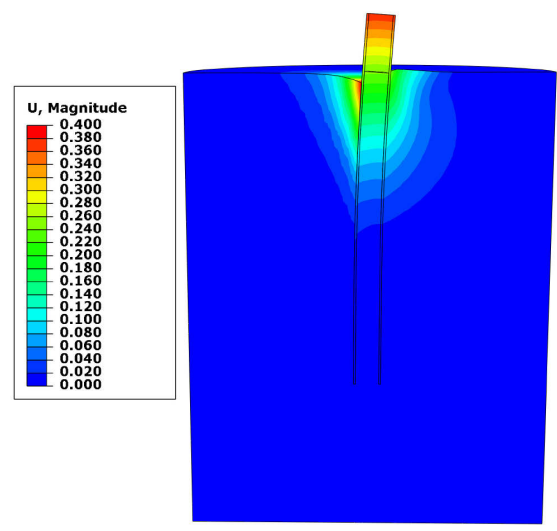

(a)

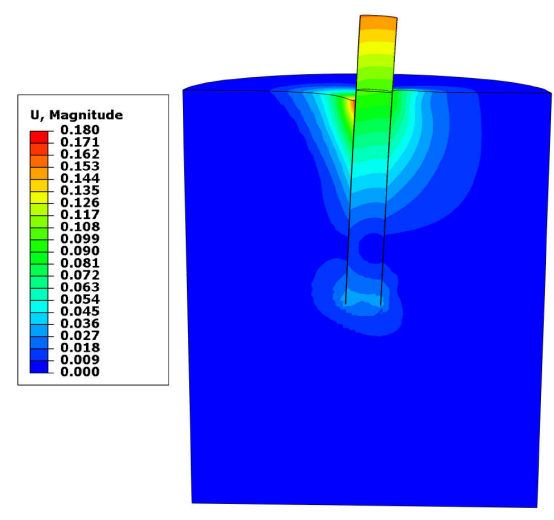

(b)

Figure 7. Displacement contour of monopile and soil under lateral loads: (a) flexible piles $\left(E_{\mathrm{s}}=30 \mathrm{MPa}, D=2.75 \mathrm{~m}, L=31.25\right.$ $\left.\mathrm{m}, E_{\mathrm{p}} I_{\mathrm{p}}=88.1 \mathrm{GN} . \mathrm{m}^{2}, \kappa=324.7\right)$; and (b) rigid piles $\left(E_{\mathrm{s}}=30 \mathrm{MPa}\right.$, $D=5.0 \mathrm{~m}, L=30 \mathrm{~m}, E_{\mathrm{p}} I_{\mathrm{p}}=2940 \mathrm{GN} . \mathrm{m}^{2}, \kappa=8.3$ ). (Deformation not in scale; cut on $\mathrm{x}-\mathrm{z}$ plane; unit: $\mathrm{m}$ )

Compared with flexible piles, significant base shear and axial resistance are mobilized at the tip of a rigid pile. Meanwhile, vertical side resistance emerges around the rigid pile shaft due to the relatively large horizontal displacement of the pile tip and rotation of the pile. Numerical investigations by Bekken (2009) and Byrne et al. (2015) have showed that the contributions due to the horizontal pile tip displacement and rotation of the pile had significant effects on the lateral response of a rigid pile. The critical conditions for taking account of the resistance from pile tip and shaft is a major concern for a laterally loaded pile in the transition zone determined by Eq. (7), which will be discussed in the next section.

\subsection{Applicability of p-y approach: scour-induced transition of monopile behavior}

For the monopile with $5.0 \mathrm{~m}$ diameter, a series of numerical simulations were conducted with various embedment depth $(L=22.5-30 \mathrm{~m})$, bending stiffness $\left(E_{\mathrm{p}} I_{\mathrm{p}} \approx 360-2940 \mathrm{GN} \cdot \mathrm{m}^{2}\right)$, and soil properties $\left(E_{\mathrm{s}}=10\right.$ $50 \mathrm{MPa}$ and $\phi=30-40^{\circ}$ ). The lateral pile displacement at the loading position obtained from the numerical results is denoted with $y_{\mathrm{n}}$. Adopting the same conditions to the numerical simulations, the lateral pile displacement at the loading position was correspondingly calculated using the parameterized approach (see Eq. (5)), denoted with $y_{\mathrm{p}}$.

Fig. 8 shows the variation of $y_{\mathrm{p}} / y_{\mathrm{n}}$ with $\kappa$. It is seen that for an approximate range of $\kappa>50$, the value of $y_{\mathrm{p}} / y_{\mathrm{n}}$ is generally equal to 1 , while the value of $y_{\mathrm{p}} / y_{\mathrm{n}}$ obviously deviates from the value of $y_{\mathrm{p}} / y_{\mathrm{n}}=1$ for $\kappa<50$. A data point from a recent study of Byrne et al. (2015) is also included in Fig. 8 (solid circle). The present results and Byrne et al.'s results are generally consistent. The deviation of $y_{\mathrm{p}} / y_{\mathrm{n}}$ implies that the tip and shaft resistance induced by the rigid pile behavior (see Figs. 6 and 7) becomes a significant part of the whole soil resistance if $\kappa<\sim 50$. The traditional $p-y$ approach only takes account of the lateral soil resistance and thus is not appropriate for predicting lateral response of a rigid pile $(\kappa<\sim 50)$.

As scour depth $S$ is predicted to scale with the pile diameter and the slenderness ratio $(D / L)$ of the typical offshore monopile is large (Qi \& Gao, 2014), the scour depth could be up to $25 \%$ of the pile embedment depth, i.e. $S / L=\sim 0.25$. The scour-induced reduction of the pile embedment depth would result in decrease of $\kappa$ (see Eq. (8)). Here we adopt $L_{\mathrm{s}}$ and $\kappa_{\mathrm{s}}$ to denote the pile embedment depth and $\kappa$ after scour, respectively. $\kappa_{\mathrm{s}}$ can be calculated by

$$
\begin{aligned}
\kappa_{s} & =E_{s} L_{s}^{4} / E_{p} I_{p} \\
& =\left(E_{s} L^{4} / E_{p} I_{p}\right)\left(L_{s} / L\right)^{4} \\
& =\kappa(1-S / L)^{4}
\end{aligned}
$$

Fig. 9 shows the variation of $\kappa_{\mathrm{s}}$ with $S / L$ for various initial values of $\kappa$. It is indicated that a scour depth of $S / L=0.15$ could approximately reduce $\kappa$ by half and further induce a transition of monopile behavior if the initial value of $\kappa$ is approximate to the critical value of $\kappa=\sim 50$ (see Fig. 8). If the pile exhibits a very rigid behavior after scour $\left(\right.$ e.g. $\left.\kappa_{\mathrm{s}}<30\right)$, the traditional $p-y$ approach would become inapplicable due to the scour-induced transition of monopile behavior (see Fig. 8).

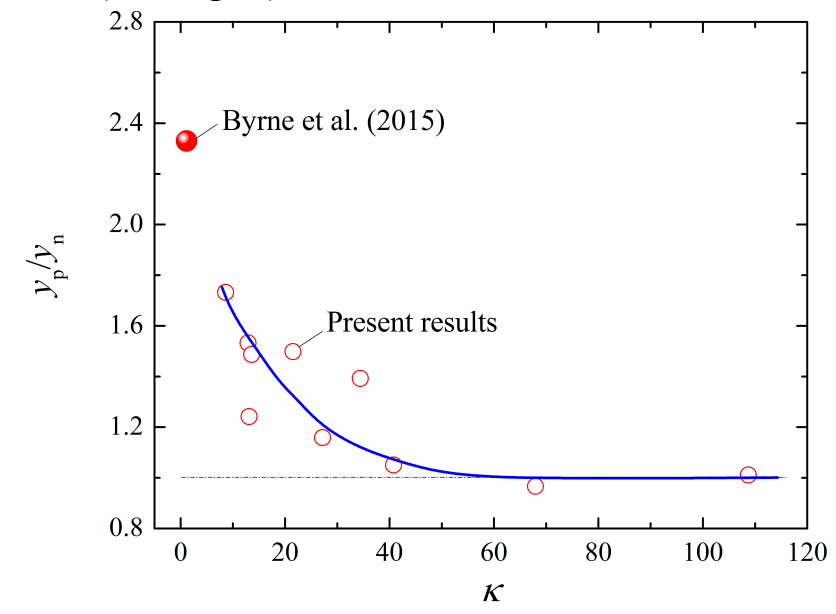

Figure 8. Variation of $y_{\mathrm{p}} / y_{\mathrm{n}}$ with $\kappa\left(=E_{\mathrm{s}} L^{4} / E_{\mathrm{p}} I_{\mathrm{p}}\right)$. 


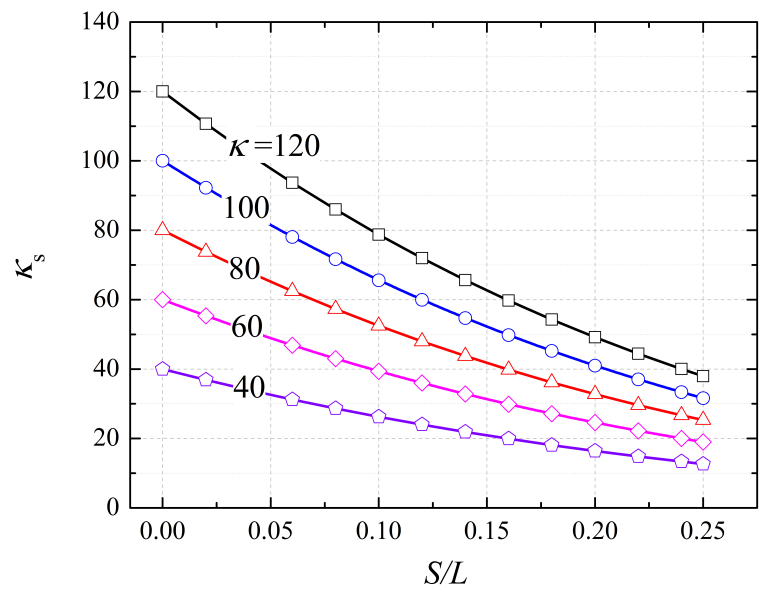

Figure 9. Effect of $S / L$ on $\kappa_{\mathrm{s}}$.

\subsection{Local scour effect: comparison with centrifuge tests}

Local scour reduces the pile embedment depth and increases the load eccentricity (relative to the base of the scour hole). Moreover, the remaining sloping overburden soil around the pile has significant effect on the pile-soil interaction.

Three numerical simulations were conducted to reveal the local scour effect on the lateral pile response, with various local scour depths adopted (i.e. $S / D=0,0.91,1.82)$, respectively. The slope angle of scour holes keeps constant at $30^{\circ}$ in these simulations. The derived $p-y$ curves at various soil depths below the scour base (i.e. $\left.z^{\prime} / D=0.53,1.37,2.28\right)$ for different local scour depths are compared in Fig. 10. The $p-y$ curves at a given depth below the scour base become significantly stiffer with increasing depth of local scour, especially at relatively shallow depths (e.g. $z^{\prime} / D=0.53$ ). This increasing stiffness of the $p-y$ curves would be attributed to the enhanced mobilization of soil at relatively shallow depth due to the sloping overburden soil, as shown in Fig. 11.

According to the results of a series of centrifuge tests, a practical approach to incorporate effects of local scour on the $p-y$ curves was proposed by adopting an effective soil depth $\left(z_{\mathrm{e}}\right)$ in the determination of $p-y$ curves (Qi et al., 2015). The effective soil depth was expressed by

$\frac{z_{e}}{D}=\frac{z^{\prime}}{D}+\tanh \left(f \frac{z^{\prime}}{D}\right) \frac{S}{D}, f \approx 1.5$ for local scour

where the effective soil depth $z_{\mathrm{e}}$ is a weightedaverage of the soil depth relative to the original mudline $z$ and the soil depth below the current scour base $z^{\prime}(=z-S), f$ is an empirical parameter indicating the transition rate for the effective soil depth from $z_{\mathrm{e}}=z^{\prime}=0$ at the current mudline to $z_{\mathrm{e}}=z$ as the soil depth increases. The recommended value of $f=1.5$ for local-scour conditions was based on the tests with $30^{\circ}$ slope angle of the scour hole.

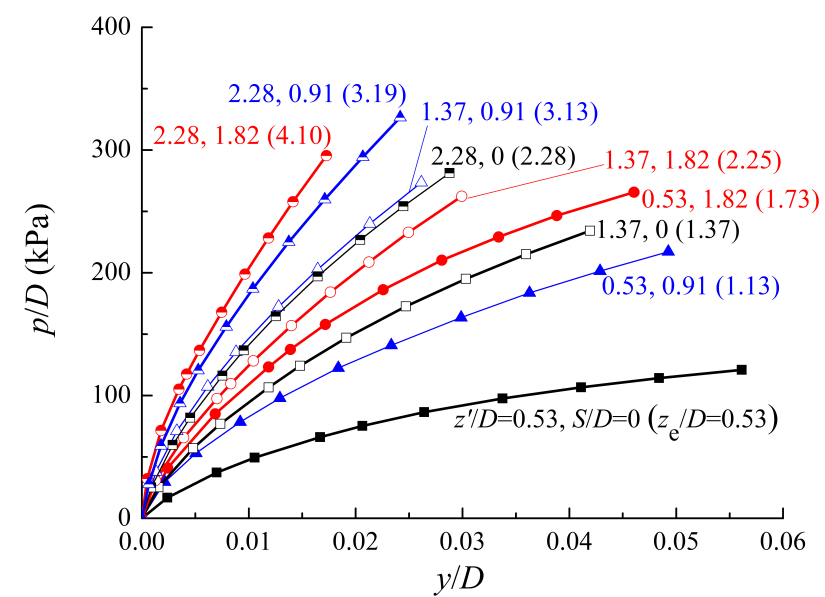

Figure 10. Local scour effect on the $p-y$ curves at various given depths below the scour base $\left(E_{\mathrm{s}}=50 \mathrm{MPa}, D=2.75 \mathrm{~m}\right.$, initial embedment depth $L=31.25 \mathrm{~m}, E_{\mathrm{p}} I_{\mathrm{p}}=88.1$ GN.m ${ }^{2}$ ).
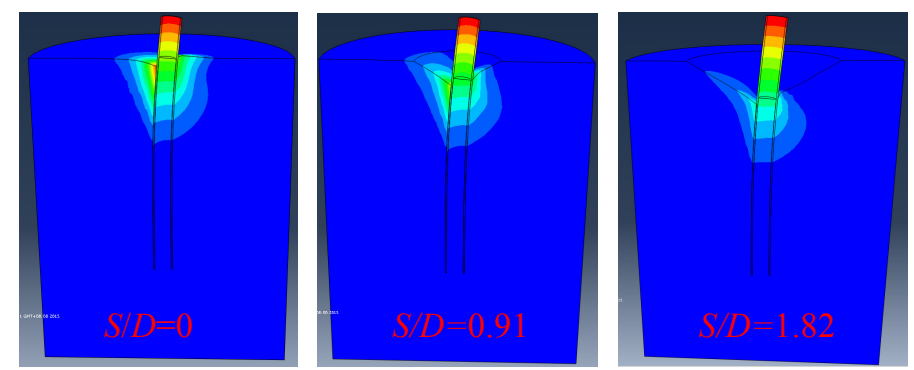

Figure 11. Displacement contour of monopile and soil under lateral loads for various local scour depths.

By adopting Eq. (10), values of the effective soil depth $z_{\mathrm{e}} / D$ for the $p-y$ curves in Fig. 10 are calculated, as shown in Fig. 10. The $p-y$ curves get progressively stiffer with ascending values of $z_{\mathrm{e}} / D$, confirming that the present numerical results are generally consistent with the centrifuge results from Qi et al. (2015).

\subsection{Dependence of local scour effect on slope angle of scour holes}

The recommended value of $f=1.5$ for local scour conditions in Eq. (10) was based on the cases with $30^{\circ}$ slope angle of scour holes. The slope angle may influence the calculation of $z_{\mathrm{e}}$, in particular, the value of $f$ in Eq. (10). For the present typical results with $30^{\circ}$ slope angle, the values of $f=1.5$ implies a transition depth of $z^{\prime} / D \approx 1.5$, i.e. $z_{\mathrm{e}} / D$ is approximately equal to $z / D$ for $z^{\prime} / D>\sim 1.5$. As the slope angle of scour holes decreases, for a given scour depth, the effect of the sloping overburden soil above the level of the scour base reduces and the transition depth becomes larger, which means the value of $f$ should be reduced accordingly. For the cases with arbitrary slope angles (generally in the range of $0-40^{\circ}$ ), further numerical simulations are needed to relate the value of $f$ to slope angle. 


\section{CONCLUSIONS}

Scour around a pile may lead to a significant reduction in the lateral stiffness and capacity of the pile, and hence the safety of the super-structure. A 3-D finite element model for the lateral pile-soil is proposed and verified. An improved analysis approach is presented for evaluating the local scour effects on pile-soil interaction by extracting $p-y$ curves from the numerical results. The following conclusions can be drawn:

(1) Scour could induce a significant transition of pile behavior for a monopile typically employed for offshore wind turbines. If the pile exhibits a very rigid behavior after scour, the tip and shaft resistance induced by the rigid pile behavior becomes a significant part of the whole soil resistance and the traditional $p-y$ approach would become inapplicable.

(2) For a given depth below the scour base, the $p-y$ curves become significantly stiffer with increasing depth of local scour, especially at relatively shallow depths. The scour effect on the variation of $p-y$ curves from the present numerical results are generally consistent with the existing centrifuge results.

(3) As the slope angle of scour holes decreases, the effect of the remaining sloping overburden soil above the level of the scour base reduces and the stiffening of the $p-y$ curves at a given depth below the scour base is correspondingly alleviated. Further numerical simulations are needed to totally reveal the effect of slope angle of scour holes.

\section{ACKNOWLEDGEMENTS}

This work was supported by the National Natural Science Foundation of China (Grant Nos. 11232012, 11372319) and the National Key Basic Research Program of China (Grant No. 2014CB046204).

\section{REFERENCES}

American Petroleum Institute. 2011. Geotechnical and foundation design considerations, ANSI/API Recommended Practice 2 GEO First Edition.

Bekken, L. 2009. Lateral behavior of large diameter offshore monopile foundations for wind turbines. Dissertation for the Doctoral Degree. TU Delft, Delft University of Technology.

Byrne, B.W, McAdam, R., Burd, H.J., et al. 2015. New design methods for large diameter piles under lateral loading for offshore wind applications. Proceedings of 3rd International Symposium on Frontiers in Offshore Geotechnics. Oslo: CRC Press.

Gao, F.P., Li, J.H., Qi, W.G., Hu, C. 2015. On the instability of offshore foundations: theory and mechanism. Science China-Physics, Mechanics \& Astronomy 58(12): 124701.
Knappett, J.A., Craig, R.R.F., 2012. Craig's Soil Mechanics. Taylor \& Francis, London.

Lin, C., Bennett, C., Han, J., et al. 2010. Scour effects on the response of laterally loaded piles considering stress history of sand. Computers \& Geotechnics 37: 1008-1014.

Lin, C., Han, J., Bennett, C., et al. 2014. Analysis of laterally loaded piles in sand considering scour hole dimensions. Journal of Geotechnical and Geoenvironmental Engineering 140(6): 04014024.

Oasys ALP. 2013. software, version 19.2, Oasys Limited.

Peng, J.R. 2006. Behaviour of Finned Piles in Sand under Lateral Loading (Ph.D thesis). Newcastle University, UK.

Poulos, H., Hull, T. 1989. The role of analytical geomechanics in foundation engineering. In Foundation engineering: Current principles and practices, Reston, VA: ASCE 2: 15781606.

Qi, W.G., Gao, F.P. 2014. Equilibrium scour depth at offshore monopile foundation in combined waves and current. Science China Technological Sciences 57(5): 1030-1039.

Qi, W.G., Gao, F.P., Randolph, M.F., Lehane, B.M. 2016. Scour effects on the p-y curves of shallowly-embedded piles in sand. Géotechnique 10.1680/jgeot.15.P.157.

Randolph, M.F., Wroth, C.P. 1981. Application of the failure state in undrained simple shear to the shaft capacity of driven piles. Géotechnique 31(1): 143-157.

Reese, L.C, Van Impe, W.F. 2001. Single piles and pile group under lateral loading. A. A. Balkema, Rotterdam.

Reese, L.C., Cox, W.R., Koop, F.D. 1974. Analysis of laterally loaded piles in sand. Proceedings of the Offshore Technology Conference, Houston, TX, paper OTC 2080. 